\title{
Benzyl butyl phthalate increases the chemoresistance to doxorubicin/cyclophosphamide by increasing breast cancer-associated dendritic cell-derived CXCL1/GRO $\alpha$ and S100A8/A9
}

\author{
YA-LING HSU ${ }^{1}$, JEN-YU HUNG ${ }^{2,3}$, EING-MEI TSAI ${ }^{1}$, CHENG-YING WU $^{1}$, YA-WEN HO ${ }^{4}$, SHU-FANG JIAN ${ }^{4}$, \\ MENG-CHI YEN ${ }^{5}$, WEI-AN CHANG ${ }^{3,4}$, MING-FENG HOU ${ }^{4}$ and PO-LIN KUO ${ }^{4,6,7}$ \\ ${ }^{1}$ Graduate Institute of Medicine, College of Medicine, Kaohsiung Medical University, Kaohsiung 807; \\ ${ }^{2}$ School of Medicine, College of Medicine, Kaohsiung Medical University, Kaohsiung 807; ${ }^{3}$ Division of Pulmonary and \\ Critical Care Medicine, Kaohsiung Medical University Hospital, Kaohsiung 807; ${ }^{4}$ Institute of Clinical Medicine, \\ College of Medicine, Kaohsiung Medical University, Kaohsiung 807; ${ }^{5}$ Department of Emergency Medicine, \\ Kaohsiung Medical University Hospital, Kaohsiung Medical University, Kaohsiung 807; \\ ${ }^{6}$ Research Center for Environmental Medicine, Kaohsiung Medical University, Kaohsiung 807; \\ ${ }^{7}$ Institute of Medical Science and Technology, National Sun Yat-Sen University, Kaohsiung 804, Taiwan, R.O.C.
}

Received June 23, 2015; Accepted August 4, 2015

DOI: 10.3892/or.2015.4307

\begin{abstract}
Phthalates are used as plasticizers in the manufacture of flexible vinyl, which is used in food contact applications. Phthalates have been demonstrated to have an adverse impact on human health, particularly in terms of cancer development. In the present study, we showed for the first time that benzyl butyl phthalate (BBP) potentiates the effect of tumor-associated dendritic cells (TADCs) on the chemoresistance of breast cancer. Specific knockdown analysis revealed that S100A9 is the major factor responsible for the chemoresistance of doxorubicin/cyclophosphamide induced by BBP-stimulated TADCs in breast cancer. BBP exposure also increased tumor infiltrating myeloid-derived suppressor cell (MDSC) secretion of S100A8/A9, thereby exacerbating the resistance of breast cancer to doxorubicin with cyclophosphamide. In addition, BBP also stimulated the production of CXCL1/GRO $\alpha$ by TADCs, which increased the angiogenesis of breast cancer in a mouse model. Inhibition of CXCL1/GRO $\alpha$ by a neutralizing antibody, decreased the BBP-induced angiogenesis induced by BBP after chemotherapy in the mouse model. These results, for the first time, provide evidence that BBP influences the efficacy of chemotherapy by remodeling the tumor microenvironment of breast cancer.
\end{abstract}

Correspondence to: Professor Po-Lin Kuo, Institute of Clinical Medicine, College of Medicine, Kaohsiung Medical University, Kaohsiung 807, Taiwan, R.O.C

E-mail: kuopolin@seed.net.tw

Key words: chemoresistance, angiogenesis, phthalate esters, breast cancer

\section{Introduction}

Food, including milk, vegetables, vegetable oil, and even school meals have been found to contain multiple types of phthalates in recent years (1-4). These different types of phthalates are transferred to food during vegetable cultivation, food packaging and food processing (5-7). Phthalates have been detected in the serum of infants, children and adults as it is difficult to avoid daily dietary exposure at present $(8,9)$. Moreover, metabolites of dibutyl phthalate (DBP), di-2-ethylhexyl phthalate (DEHP) and benzyl butyl phthalate (BBP), have been found in urine, serum, breast milk and saliva. Studies have revealed that phthalate exposure is associated with many diseases, such as airway obstruction, allergies, asthma, reproductive disease and breast cancer (10-12). BBP has been demonstrated to induce neoplastic transformation of breast epithelial cells and to increase the proliferation and progression of both estrogendependent and -independent breast cancer stem cells and cancer cells (13-16). However, the influence of phthalates on cancer therapy has not been evaluated to date.

Breast cancer is the most common female cancer, and is one of the major causes of cancer-related mortality among women. There were nearly 1.7 million new breast cancer cases diagnosed and 521,900 deaths due to breast cancer worldwide in $2012(17,18)$. Although chemotherapy significantly improves the outcome of patients with breast cancer, chemoresistance is still a major obstacle to successful treatment and such resistance to chemotherapeutic drugs frequently results in subsequent tumor recurrence and tumor metastasis $(19,20)$. However, most of the mechanisms responsible for resistance to chemotherapeutic agents are still unknown. A better understanding of the causes and mechanisms of chemoresistance can be helpful for identifying and developing novel therapeutic 
agents that could decrease metastasis, chemoresistance, and even cancer-related death.

The tumor microenvironment (TME) not only plays a critical role during tumorigenesis, cancer progression and metastasis, but also influences therapeutic efficacy (21). Tumor environment-mediated drug resistance (EMDR) is mediated by a multitude of reciprocal interactions between cancer cells and various cell types existing in the TME. Tumor-associated immune cells are a hallmark of most solid malignancies, and the presence of various immune cells significantly influences clinical outcome (22). Tumor-associated macrophages have been indicated to increase the resistance of cancer against cytotoxic agents. Therefore, inhibiting the infiltration of macrophages improves the efficacy of chemotherapy and reduces cancer metastasis $(23,24)$. Similar to macrophages, tumor-associated dendritic cells (TADCs) have been postulated as being involved in cancer progression (25-27). TADCs produce a number of potent growth factors and cytokines, which may be mediators that potentiate chemoresistance $(28,29)$. The present study is the first to assess the effects of BBP on breast cancer, and to demonstrate that BBP induces a change in the chemosensitivity of breast cancer to doxorubicin/cyclophosphamide by altering the cancer microenvironment.

\section{Materials and methods}

Cell culture and conditioned medium. Human breast adenocarcinoma cell line MDA-MB-231 (ATCC HTB-26 ${ }^{\mathrm{TM}}$; American Type Culture Collection, ATCC, Manassas, VA, USA) was cultured in Leibovitz medium (L15) supplemented with $1 \%$ antibiotic solution and $10 \%$ fetal bovine serum (FBS) (all from Thermo Fisher Scientific, Waltham, MA, USA) in a $\mathrm{CO}_{2}$-free incubator. Human umbilical vein endothelial cells (HUVECs) (BCRC H-UV001; Bioresource Collection and Research Center, Hsinchu, Taiwan) and 4T1 mouse mammary tumor cell line (ATCC CRL-2539; ATCC) were cultured in complete EGM2 medium (Lonza, Walkersville, MD, USA), or RPMI-1640 (Gibco-BRL, Gaithersburg, MD, USA) medium containing $10 \% \mathrm{FBS}$ in a $5 \% \mathrm{CO}_{2}$ incubator. To prepare the conditioned media (CM), the MDA-MB-231 cells $\left(2 \times 10^{6} / 100 \mathrm{~mm}\right.$ dish) were seeded, and the supernatant was harvested and filtered $(0.22 \mathrm{~mm})$, after $48 \mathrm{~h}$ of incubation.

Isolation of $\mathrm{CDI}^{+}$monocytes and differentiation of dendritic cells. Monocytes were isolated from peripheral blood mononuclear cells (PBMCs) provided by healthy consenting donors. PBMCs were isolated from blood by Ficoll-Hypaque gradient (GE Healthcare Bio-Sciences, Little Chalfont, UK). CD14 ${ }^{+}$monocytes were purified from PBMCs by using $\mathrm{CD} 14^{+}$monoclonal antibody-conjugated magnetic beads (MACS MicroBeads; Miltenyi Biotec Ltd., Bergisch Gladbach, Germany), according to the manufacturer's procedure. Monocyte-derived dendritic cells (mdDCs) or TADCs were generated by culturing $\mathrm{CD} 14^{+}$monocytes in RMPI-1640 medium containing control 20\% L15 (for mdDCs) or MDA-MB-231-CM (for TADCs) presenting in $10 \mathrm{ng} / \mathrm{ml}$ GM-CSF and IL-4 (R\&D Systems, Minneapolis, MN, USA), with or without BBP (1 or $10 \mu \mathrm{M}$; Sigma-Aldrich, St. Louis, MO, USA) for 5 days. The mdDC and TADC supernatants were collected and filtered $(0.22 \mathrm{~mm})$ to be used as CMs.
The Institutional Review Board (IRB) of Kaohsiung Medical University Hospital (Kaohsiung, Taiwan) approved the study protocol, and all of the participants provided written informed consent in accordance with the Declaration of Helsinki (IRB no. KMUH-IRB-990174 and KMUH-IRB-20120362).

Measurement of secreted factors. Supernatants from the mdDCs or TADCs treated with or without BBP were collected. CXCL1/GRO $\alpha$ and VEGF were determined by Milliplex MAP kit (Millipore, Billerica, MA, USA). S100A8 and S100A9 were assessed and quantified using the DuoSet ELISA (enzymelinked immunosorbent assay; R\&D Systems).

Cell viability/apoptosis. MDA-MB-231 cells were treated with control or doxorubicin/cyclophosphamide $(10 / 100 \mu \mathrm{M})$ with or without BBP $(1 \mu \mathrm{M})$ presenting in various CMs $(20 \%)$ for 48 h. Cell viability was determined by Premixed WST-1 Cell Proliferation reagent (Clontech Laboratories Inc., Mountain View, CA, USA) in accordance with the manufacturer's instructions. Quantitative analysis of apoptosis was determined by the terminal nucleotidyl transferase-mediated nick end labeling (TUNEL) method using the BD ApoAlert DNA Fragmentation Assay kit (BD Biosciences Clontech, Palo Alto, CA, USA).

Tube formation analysis. Tube formation assays were carried out as described previously after modification (30). Growth factor-reduced Matrigel (200 $\mu \mathrm{l})$ was loaded in each well of a 24-well plate, which was incubated at $37^{\circ} \mathrm{C}$ for $60 \mathrm{~min}$. HUVECs were mixed with the various CMs (20\%) and the CXCL1/GRO $\alpha$ antibody. Cell suspension solution (500 $\mu \mathrm{l})$ was added on top of the Matrigel. The plate was then incubated at $37^{\circ} \mathrm{C}$, and the formation of capillary-like tubes was detected and stained using Calcein-AM (Life Technologies, Carlsbad, CA, USA) after $10 \mathrm{~h}$ using a fluorescence microscope.

RNA isolation and quantitative reverse transcriptase-polymerase chain reaction ( $q R T-P C R)$. Total RNA was isolated using TRIzol reagent (Invitrogen Life Technologies) according to the manufacturer's protocol, and reverse transcribed to cDNA using a SuperScript III Reverse Transcriptase kit (Invitrogen). PCR mixture was prepared using the SYBR Green qPCR kit (Invitrogen) and using the following primers as follows: CXCL1/GRO $\alpha$ (forward, 5'-agggaattcaccccaagaac-3' and reverse, 5'-TAACTATGGGGGATGCAGGA-3'); S100A8 (forward, 5'-atgcegtctacagggatgac-3' and reverse, 5'-ACGC CCATCTTTATCACCAG-3') and GAPDH (forward, 5'-TT CACCACCATGGAGAAGGC-3' and reverse, 5'-GGCATG GACTGTGGTCATGA-3'). All qRT-PCR reactions were performed using the StepOne Real-Time PCR system (Applied Biosystems, Foster City, CA, USA). Quantitative analysis normalized to GAPDH was performed according to the comparative cycle threshold $(\mathrm{Ct})$ method.

CXCL1/GRO $\alpha$ and S100A9 knockdown. CD14+ monocytes were transfected with $1 \mu \mathrm{M}$ non-targeting, CXCL1/ GRO $\alpha$ or S100A9 Accell ${ }^{\mathrm{TM}}$ SMARTpool siRNA (Thermo Fisher Scientific) containing IL-4 and GM-CSF for 5 day. The medium containing siRNA and IL-4/GM-CSF was replaced on day 3. The knockdown efficacy of siRNA was measured by qRT-PCR. 
Animal experiments and drug treatment. For the orthotopic metastasis assay, mouse breast cancer 4T1 cells were transplanted into the mammary fat pads of 8 -week-old female BALB/c mice. Mice were injected once a week with either PBS vehicle, BBP, doxorubicin hydrochloride $(2 \mathrm{mg} / \mathrm{kg}) / \mathrm{cyclo}-$ phosphamide monohydrate $(60 \mathrm{mg} / \mathrm{kg})$ or a combination of BBP and PBS vehicle, BBP, doxorubicin hydrochloride (2 mg/kg)/cyclophosphamide monohydrate $(60 \mathrm{mg} / \mathrm{kg})$ for 3 weeks. For experiments involving CXCL1/GRO $\alpha$ inhibition, the mice were injected intraperitoneally with either IgG (vehicle) or with CXCL1/GRO $\alpha$ once per week (50 $\mu \mathrm{g} /$ mouse). All immunohistochemical reactions were performed on $5-\mu \mathrm{m}$ paraffin sections. In brief, the sections were deparaffinized in xylene and rehydrated, and then incubated in target retrieval solution (DAKO) in an autoclave for $8 \mathrm{~min}$ to retrieve the antigens. Endogenous peroxidase activity was blocked by $10 \mathrm{~min}$ of incubation with a $3 \%$ solution of $\mathrm{H}_{2} \mathrm{O}_{2}$. The expression of CD31 antigen was assessed using the mouse monoclonal anti-CD31 (dilution 1:100) antibody. The sections were incubated with the primary antibodies overnight at $4^{\circ} \mathrm{C}$. The antigens were then visualized using biotinylated antibodies and streptavidin, conjugated with horseradish peroxidase. Diaminobenzidine (DakoCytomation, Glostrup, Denmark) served as the substrate, and all of the sections were counterstained with hematoxylin.

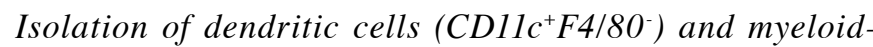
derived suppressor cells (MDSCs) from the mice. Mouse mammary tumors (4T1-bearing mice) were collected and minced. Single-cell suspensions were obtained after enzymatic digestion ( $1 \mathrm{mg} / \mathrm{ml}$ collagenase A; Roche Diagnostics) and $100 \mathrm{IU} / \mathrm{ml}$ type I DNase (Sigma-Aldrich) for $2 \mathrm{~h}$ at $37^{\circ} \mathrm{C}$ in RPMI-1640 medium. A single-cell suspension was filtered through a $70-\mu \mathrm{m}$ nylon mesh (BD Biosciences), and cells were washed twice with PBS. CD11 $\mathrm{c}^{+}$cells were purified using anti-CD11c monoclonal antibody-conjugated magnetic beads (MACS MicroBeads). F4/80 ${ }^{+}$cells were depleted from $\mathrm{CD} 1 \mathrm{c}^{+}$cells by using $\mathrm{F} 4 / 80^{+}$antibody-biotin beads (MACS MicroBeads). MDSCs were isolated from tumors using the Myeloid-Derived Suppressor Cell Isolation kit from Miltenyi Biotec. Cell purity was checked by flow cytometric (BD Biosciences, Franklin Lakes, NJ, USA) analysis using antiCD11b and Gr-1 antibodies ( $>75 \%$ ), and the viability was assessed by trypan blue dye exclusion.

Statistical analysis. Data are expressed as means \pm SD. Statistical analyses between the control and experimental groups were analyzed by an unpaired Student's t-test. Multiple comparisons were evaluated by one-way ANOVA, and differences in the mean values among groups were conducted by a Turkey post hoc analysis. P-values $<0.05$ were considered to indicate statistically significant differences.

\section{Results}

BBP increases chemoresistance in a $4 T 1$ orthotopic metastasis model. First, we assessed the influence of BBP on chemotherapeutic efficacy in breast cancer in a mouse model. As shown in Fig. 1, combination of doxorubicin hydrochloride $(2 \mathrm{mg} / \mathrm{kg}$ body weight) and cyclophosphamide monohydrate $(60 \mathrm{mg} / \mathrm{kg}$ body weight), a doublet chemotherapy frequently used in the clinic, exhibited a markedly inhibitory effect on cancer metastasis (lung, liver and peritoneal metastasis). Exposure of mice to BBP alone did not affect the metastasis of 4T1 in the mouse model, but did reduce the inhibitory effect of chemotherapy on breast cancer peritoneal metastasis in the mice (Fig. 1).

$B B P$ increases the chemoresistance of breast cancer via the TADC-mediated response. Since exposure to BBP increases the resistance of cancer to doxorubicin/cyclophosphamide treatment, we assessed whether BBP affects the sensitivity of breast cancer to doxorubicin/cyclophosphamide. As shown in Fig. 2A, doxorubicin/cyclophosphamide $(10 / 100 \mu \mathrm{M})$ decreased the cell viability of MDA-MB-231 cells $\sim 60 \%$ after a $48-\mathrm{h}$ treatment. However, BBP did not affect the sensitivity of breast cancer cells to the doxorubicin/cyclophosphamide combination (Fig. 2A). TME is considered to determine the efficacy of chemotherapy (31). To assess whether BBP increases the chemoresistance of breast cancer by stimulating TADCs, we generated mdDCs, TADCs and BBP-stimulated mdDCs and TDACs (BBP-mdDCs and BBP-TADCs) and collected the condition media (CM) as described in Fig. 2B. MDA-MB-231 cells were treated with doxorubicin/cyclophosphamide in regular culture medium, mdDC-CM, TADC-CM, BBP-mdDC-CM or BBP-TADC-CM containing medium. TADC-CM significantly decreased the sensitivity of the MDA-MB-231 cells to doxorubicin/cyclophosphamide. BBP further desensitized breast cancer to doxorubicin/cyclophosphamide (Fig. 2C). Next, we investigated whether the chemoresistance induced by TADC-CM and BBP-TADC-CM was mediated by reducing doxorubicin/cyclophosphamide-induced apoptosis. TADC-CM markedly reduced the percentage of TUNEL-positive MDA-MB-231 cells following treatment with doxorubicin/ cyclophosphamide relative to mdDC-CM. A statistically significant reduction in apoptosis induction was noted after exposure to BBP-TADC-CM (Fig. 2D). These data suggest that BBP stimulated soluble factor(s) secreted from TADCs to induce doxorubicin/cyclophosphamide resistance in breast cancer.

TADC-mediated S100A8/A9 increases breast cancer chemoresistance. Next, we assessed the influence of $\mathrm{BBP}$ on the expression of secretory cytokines in TADCs, which have been reported to be involved in the development of chemoresistance. The expression levels of CXCL1/GRO $\alpha, \mathrm{S} 100 \mathrm{~A} 8$ and S100A9 were increased in the TADCs, in comparison to the levels in the mdDCs. BBP further enhanced the stimulatory effect of breast cancer cells in regards to the secretion of CXCL1/GRO $\alpha$, S100A8 and S100A9, but not VEGF and OSM (Fig. 3A-E). Transplantation of the 4T1 cell into mice increased the expression of CXCL1/GRO $\alpha, \mathrm{S} 100 \mathrm{~A} 8$ and S100A9 in the TADCs $\left(\mathrm{CD} 11 \mathrm{c}^{+} \mathrm{F} 4 / 80^{-}\right)$, compared to the control mice. Exposure to BBP further increased expression of CXCL1/GRO $\alpha$, S100A 8 and S100A9 in the TADCs in the the 4T1-bearing mice (Fig. 3F and G).

To explore which secretory factors contribute to the chemoresistance of MDA-MB-231 cells, we inhibited the expression of CXCL1/GRO $\alpha$ or S100A9 using siRNA transfection. Transfection of $\mathrm{CD} 14^{+}$monocytes decreased the CXCL1/GRO $\alpha$ and S100A9 expression by 80 and $90 \%$, respectively (Fig. 4A). Inhibition of S100A9 expression prevented the 

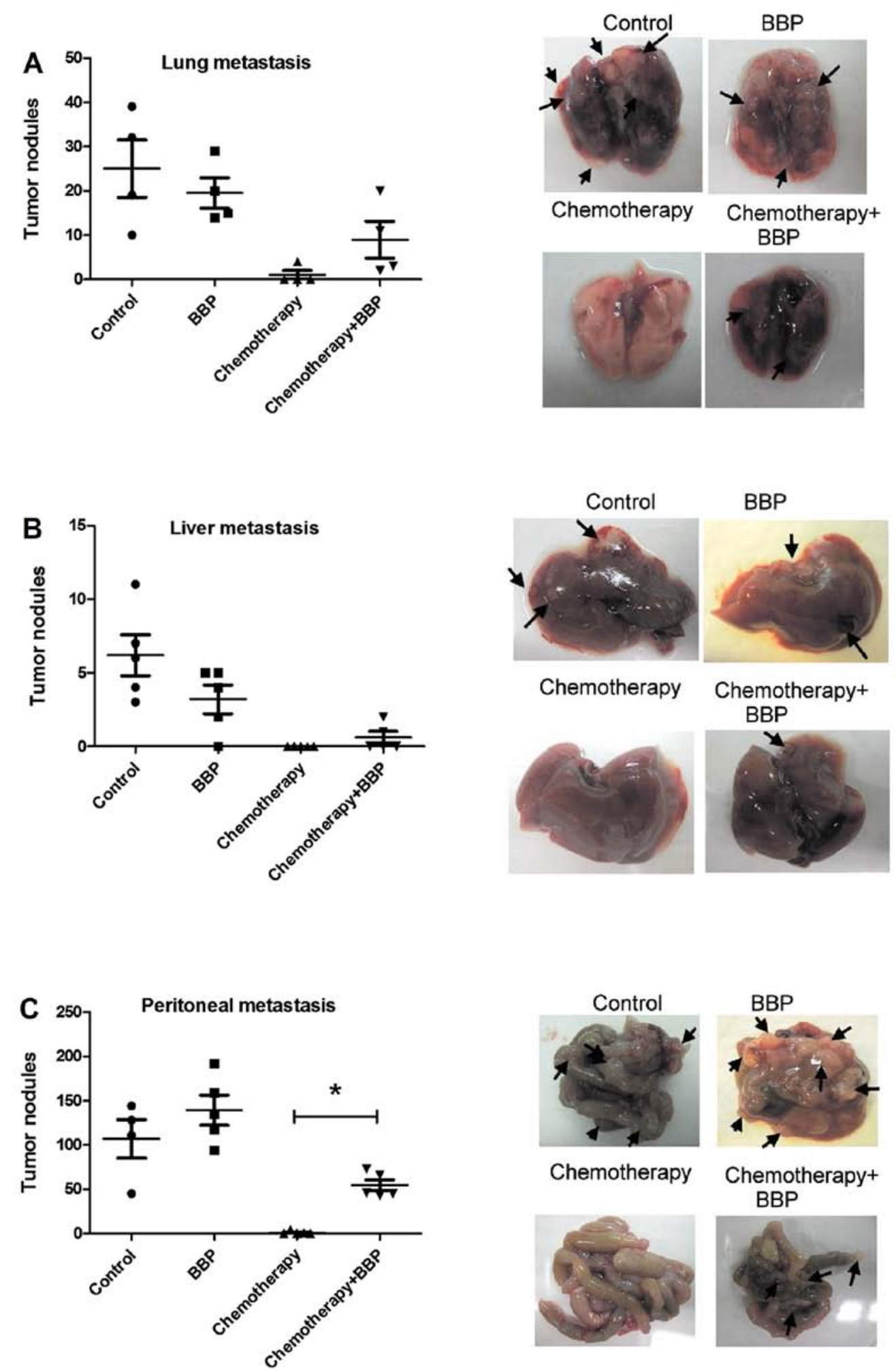

Figure 1. BBP increases anticancer drug resistance in mice. The lungs (A), liver (B) and peritoneal (C) in 4T1-bearing mice. 4T1 cells were implanted into the mammary fat pads of BALB/c mice. The mice were then randomly divided into 4 groups: a control group, a doxorubicin hydrochloride (2 mg/kg body weight) and cyclophosphamide monohydrate $(60 \mathrm{mg} / \mathrm{kg}$ body weight) (1 time/week, i.p.) administration group, a BBP administration (500 mg/kg body weight) (3 times/week, i.p.) group, and a doxorubicin/cyclophosphamide + BBP group. The control group was given an equal volume of normal saline. Tumor-bearing mice were sacrificed 4 weeks after transplantation. Their organs were removed and the metastatic tumor nodules counted. All results are representative of at least three independent experiments, and each value is the mean $\pm \mathrm{SD}$ of three determinations. The results are reported as mean $\pm \mathrm{SD} ;{ }^{*} \mathrm{P}<0.05$.

effect of CMs of BBP-derived TADCs on the chemoresistance of the MDA-MD-231 cells (Fig. 4B). However, knockdown of CXCL1/GRO $\alpha$ did not restore the chemosensitivity of
MDA-MB-231 cells to doxorubicin/cyclophosphamide in presenting CMs of BBP-derived TADCs (Fig. 4B). Similarly, only recombinant human S100A8/A9 (rhS100A8/A9) reduced 

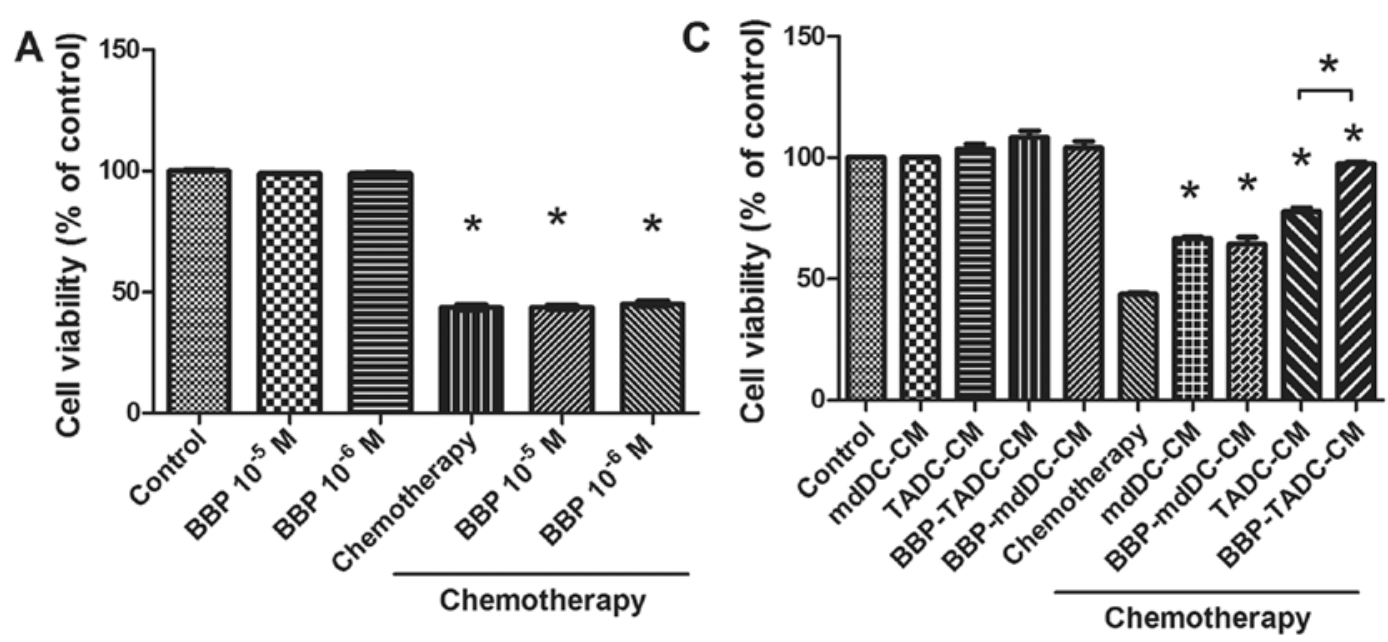

B
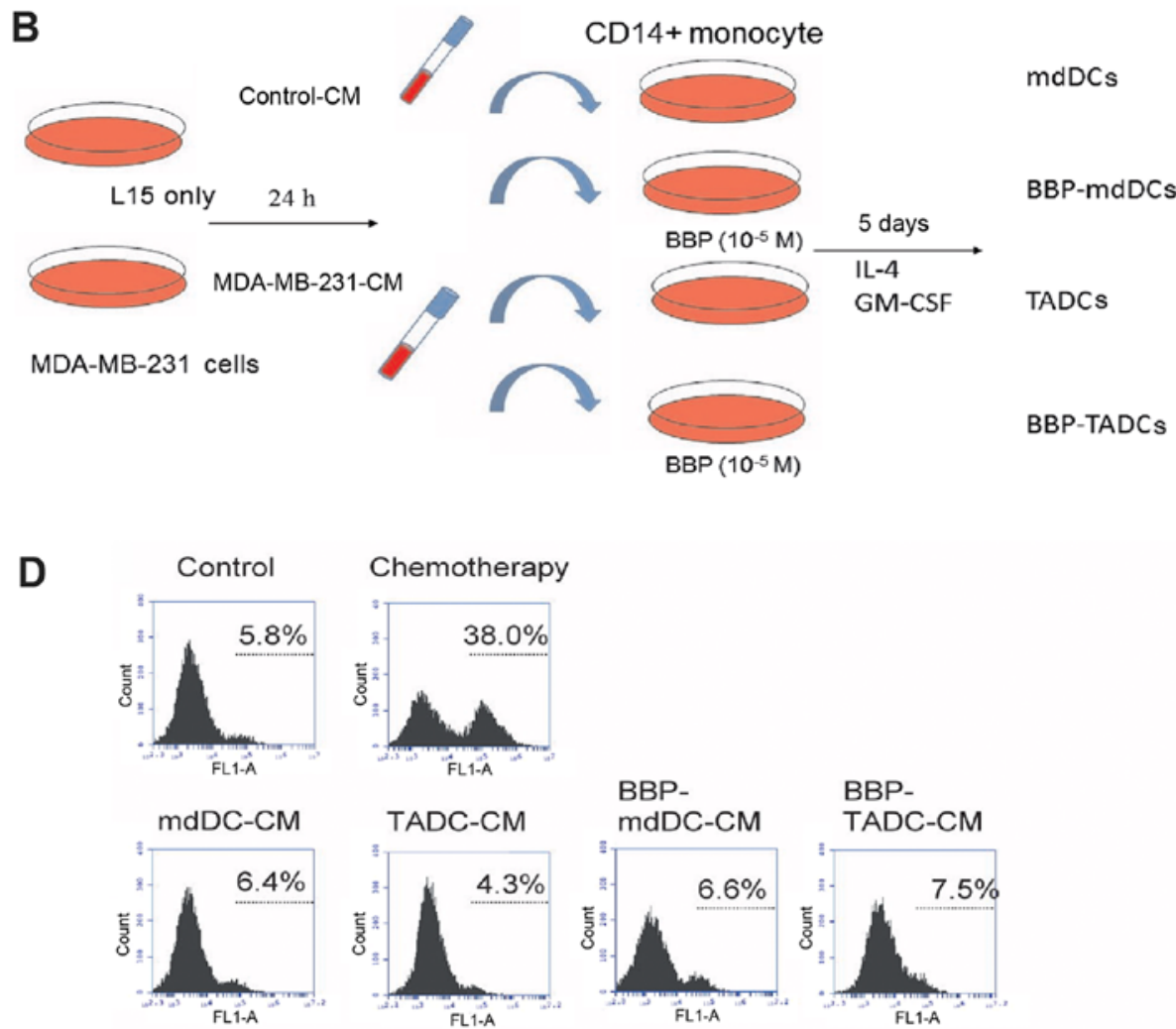

BBP-

TADC-CM
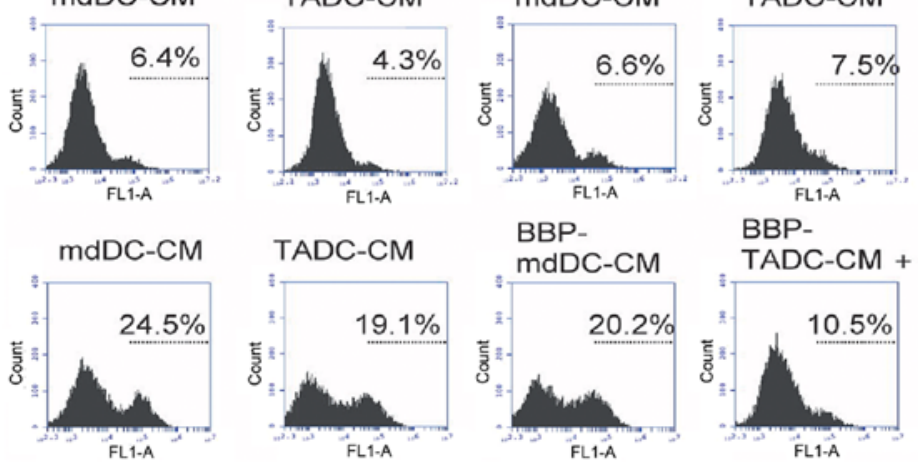

$$
\text { BBP- }
$$

TADC-CM + Chemotherapy

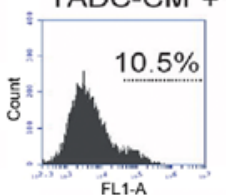

Figure 2. TADCs contribute to BBP-mediated chemoresistance. (A) BBP did not affect the cytotoxicity of doxorubicin/cyclophosphamide in MDA-MB-231 cells. Cells were treated with control $(0.1 \%$ DMSO), BBP $(1$ or $10 \mu \mathrm{M})$, doxorubicin/cyclophosphamide $(10 / 100 \mu \mathrm{M})$ or doxorubicin/cyclophosphamide $(10 / 100 \mu \mathrm{M})+\mathrm{BBP}(1$ or $10 \mu \mathrm{M})$ for $48 \mathrm{~h}$, and cell viability was determined by WST-1. (B) Flowchart for the collection of various conditioned media (CMs). (C) TADC-CM increased the resistance of MDA-MB-231 cells against doxorubicin/cyclophosphamide. Cells were treated with control or doxorubicin/cyclophosphamide $(10 / 100 \mu \mathrm{M})$ cultured in various CMs $(20 \%)$ for $48 \mathrm{~h}$, and cell viability was determined by WST-1. (D) TADC-CM decreased doxorubicin/ cyclophosphamide-mediated apoptosis in MDA-MB-231 cells. Cell were treated with control or doxorubicin/cyclophosphamide (10/100 $\mu \mathrm{M})$ cultured in various CMs (20\%) for $48 \mathrm{~h}$, and cell viability and apoptosis was determined by WST-1 and TUNEL analysis, respectively. All results are representative of at least three independent experiments, and each value is the mean $\pm \mathrm{SD}$ of three determinations. The results are reported as mean $\pm \mathrm{SD}$; $\mathrm{P}<0.05$.

the cytotoxicity of doxorubicin/cyclophosphamide, whereas recombinant human CXCL1/GRO (rhCXCL1/GRO) did not affect the cytotoxicity of doxorubicin/cyclophosphamide in the MDA-MB-231 cells (Fig. 4C and D). 
A
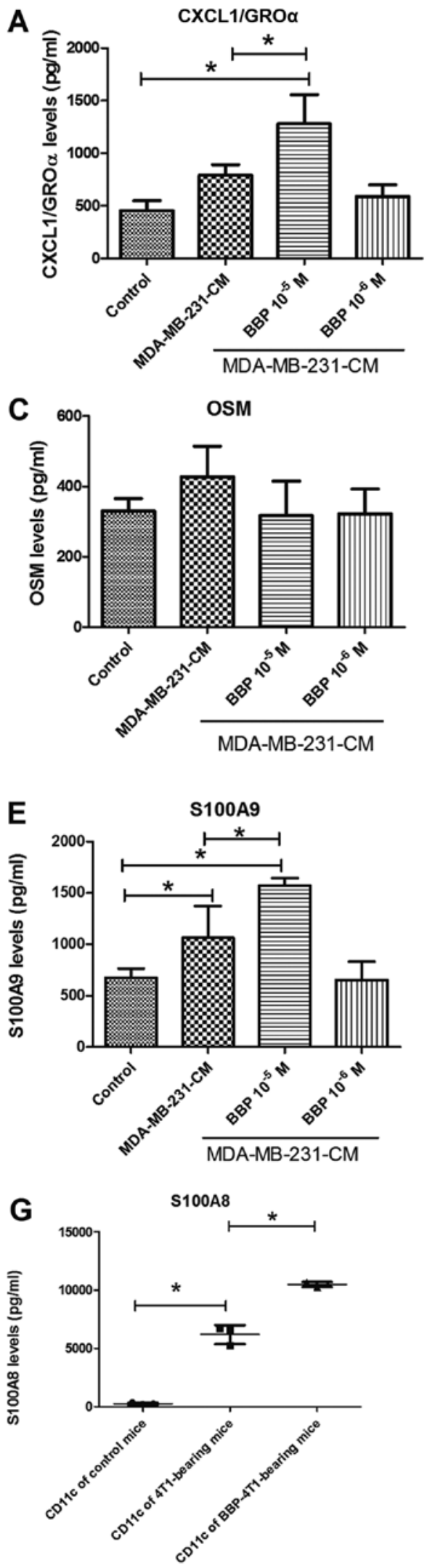
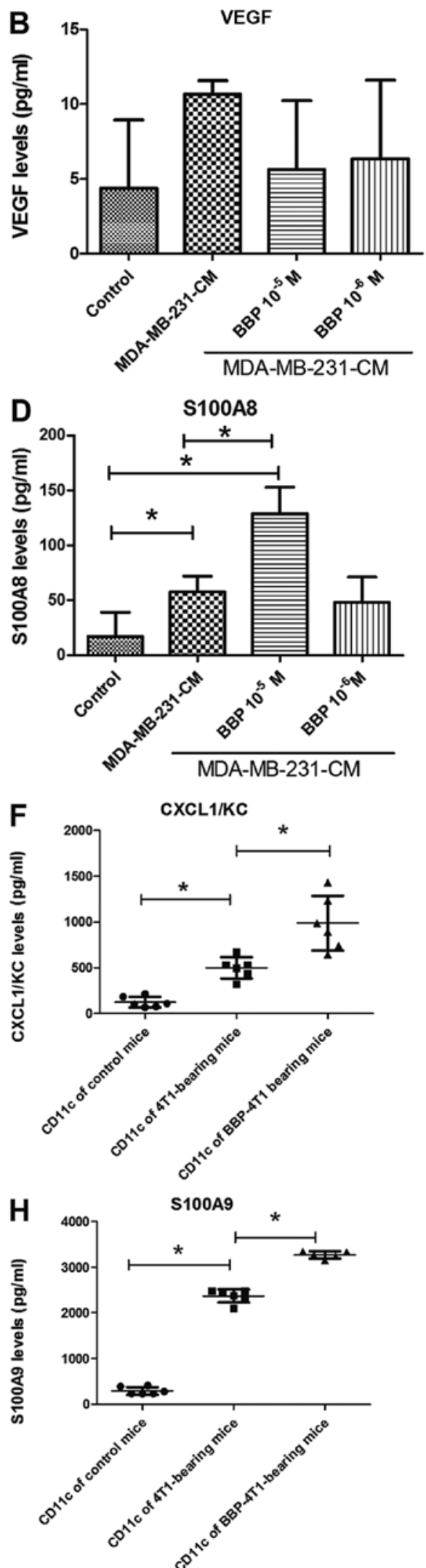

Figure 3. BBP increases the expression of CXCL1/GRO $\alpha$ and S100A8/A9 in TADCs. The effect of BBP on the expression of CXCL1/GRO $\alpha$ (A), VEGF (B), OSM (C), S100A8 (D) and S100A9 (E) in the TADCs. mdDCs and TADCs were derived by culturing CD14 $4^{+}$monocytes in RPMI-1640 medium containing GM-CSF and IL-4 with or without MDA-MB-231-CM (20\%) for 5 days. BBP-treated mdDCs and TADCs were generated using the same procedure but containing BBP $(10 \mu \mathrm{M})$. The expression of various proteins in the supernatants was determined by Milliplex MAP kit. BBP increased the expression of CXCL1 (F), S100A8 (G) and S100A9 (H) in the TADCs of the mice. 4T1 cells were implanted into mammary fat pads of BALB/c mice who were then randomly divided into 2 groups: the BBP-treated group was given i.p. with BBP $(500 \mathrm{mg} / \mathrm{kg}$ of body weight, 3 times/week) while the control group was given an equal volume of normal saline. Tumor-bearing mice were sacrificed 28 days after transplantation. TADCs (CD11c $\left.\mathrm{F} 4 / 80^{-}\right)$were isolated from the mammary tumors (4T1). The proteins in the supernatant of isolated cells were determined by ELISA kits. All results are representative of at least three independent experiments, and each value is the mean $\pm \mathrm{SD}$ of three determinations. The results are reported as mean $\pm \mathrm{SD} ;{ }^{*} \mathrm{P}<0.05$. 

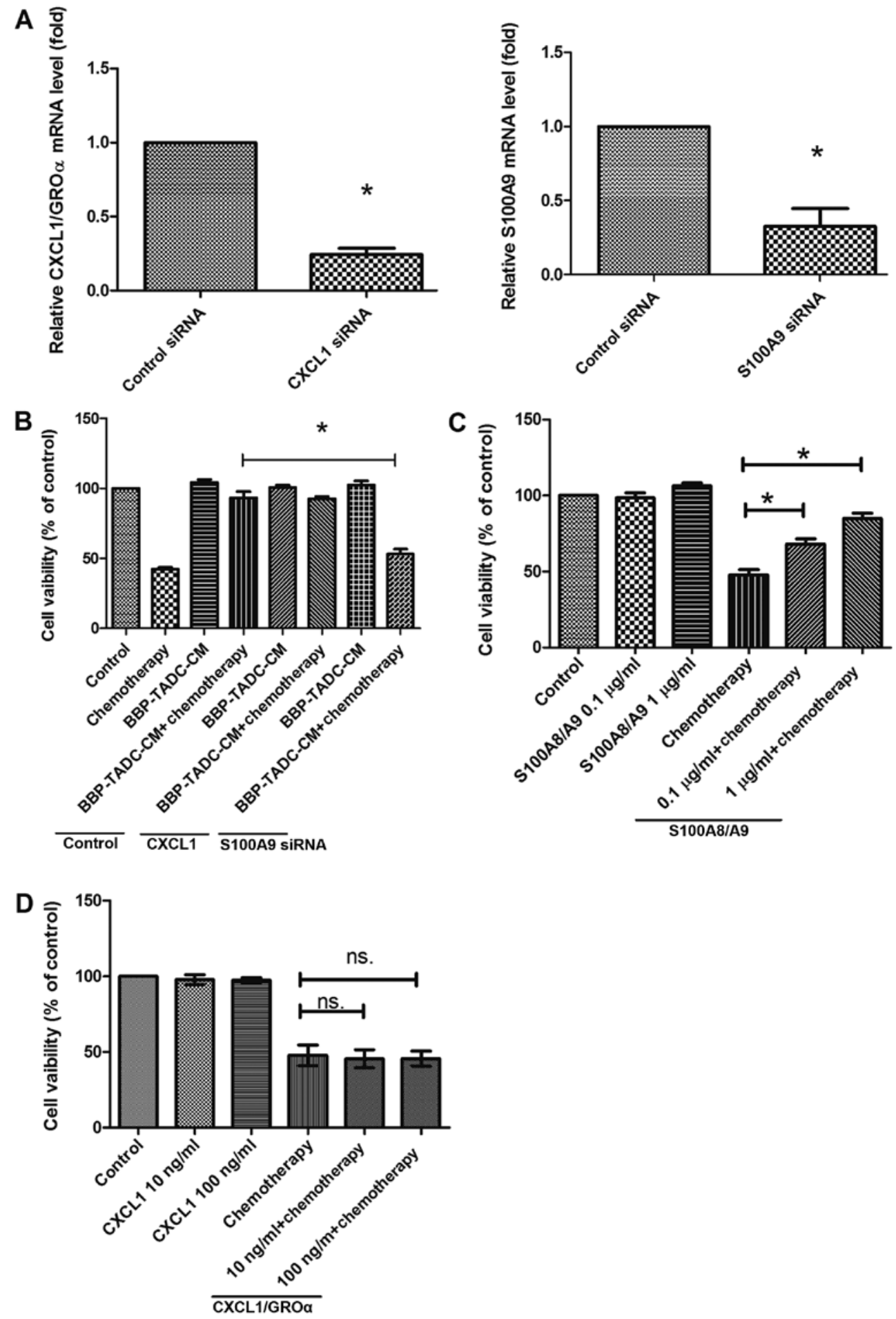

Figure 4. S100A9 contributes to TADC-mediated chemoresistance in MDA-MB-231 cells. (A) The knockdown efficacy of CXCL1/GRO $\alpha$ and S100A9 siRNA transfection. CXCL1/GRO $\alpha$ and S100A9 knockdown was performed by Accell scramble, CXCL1/GRO $\alpha$ or S100A9 siRNA (1 $\mu$ M). Knockdown efficacy was confirmed by qRT-PCR. (B) Inhibition of S100A9 decreased the chemoresistance induced by BBP-TADC-CM in the MDA-MB-231 cells. (C) rhS100A8/A9 protein decreased the sensitivity of MDA-MB-231 cells to doxorubicin/cyclophosphamide. (D) rhCXCL1/GRO $\alpha$ did not affect chemoresistance induced by BBP-TADC-CM in the MDA-MB-231 cells. Cells were treated with control or doxorubicin/cyclophosphamide $(10 / 100 \mu \mathrm{M})$ cultured in various CMs (20\%) for $48 \mathrm{~h}$, and cell viability was determined. Cells were treated with control or doxorubicin/cyclophosphamide $(10 / 100 \mu \mathrm{M})$ with or without recombinant human proteins (rhS100A8/A9 and rhCXCL1, 10-1,000 ng/ml) for $48 \mathrm{~h}$, and cell viability was determined. All results are representative of at least three independent experiments, and each value is the mean $\pm \mathrm{SD}$ of three determinations. The results are reported as mean $\pm \mathrm{SD}$; $\mathrm{P}<0.05$; ns., not significant.

BBP increases the production of S100A8 and S100A9 in MDSCs $\left(C D 11 b^{+} L y 6 C G r-1^{+}\right)$in breast cancer. Previous research has demonstrated that S100A8/A9 levels are associated with the infiltration of MDSCs in tumors and enhance chemoresistance $(31,32)$. Therefore, we assessed whether BBP increases the infiltration of MDSCs in the 4T1 cell-bearing mice. As shown in Fig. 5A and B, doxorubicin/cyclophosphamide treatment decreased the infiltration of $\mathrm{CD} 11 \mathrm{~b}^{+} \mathrm{Ly} 6 \mathrm{CGr}-\mathrm{1}^{+}$ MDSCs in the tumors. BBP exposure prevented the effect of chemotherapy on the infiltration of CD11b $\mathrm{b}^{+} \mathrm{Ly} 6 \mathrm{CGr}-\mathrm{1}^{+}$ 

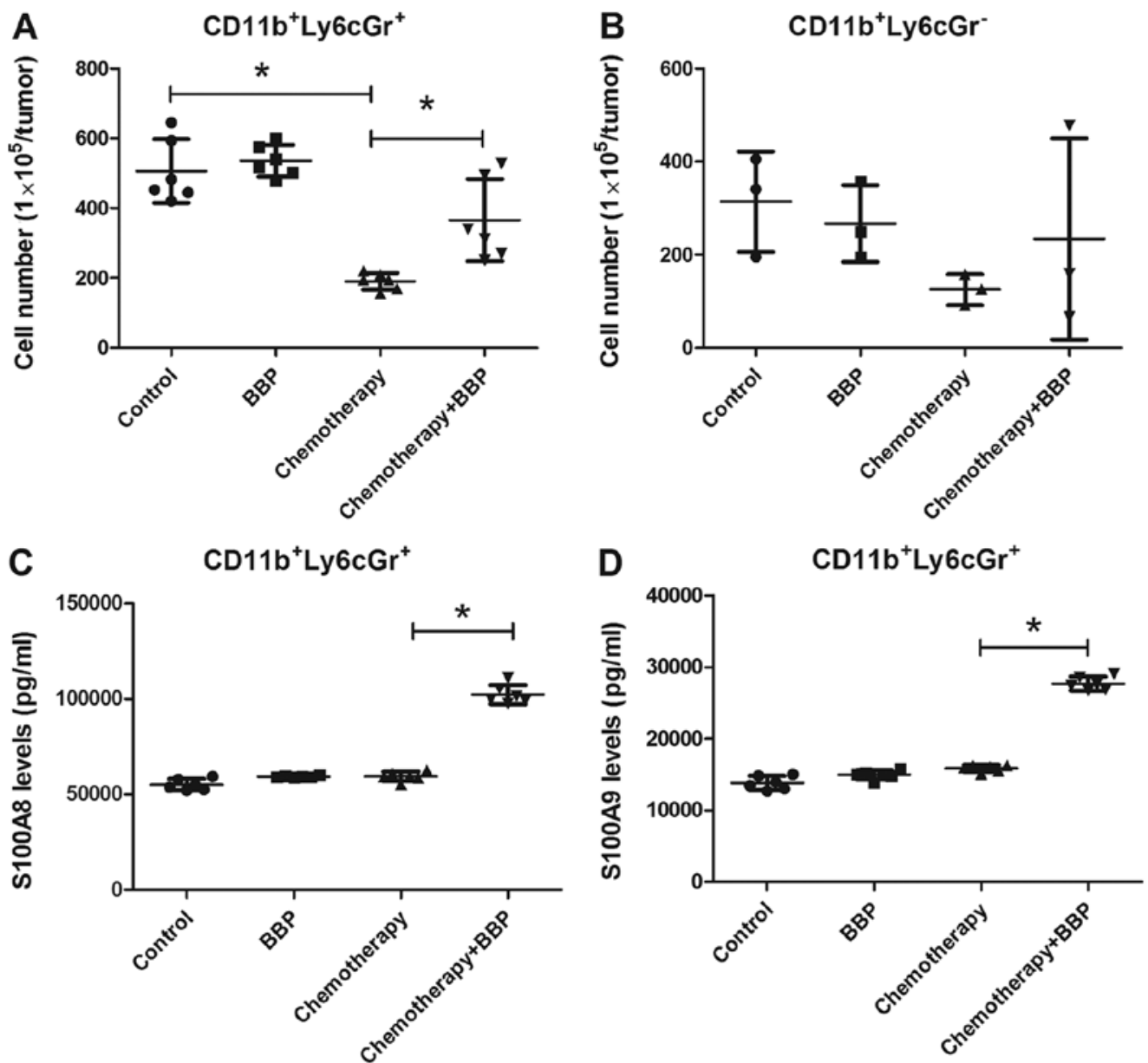

Figure 5. BBP increases the expression of S100A8 and S100A9 in MDSCs. BBP prevented the effect of doxorubicin/cyclophosphamide on the infiltration of CD11 ${ }^{+}$Ly6CGr-1+ MDSCs (A), but did not reverse the effect of doxorubicin/cyclophosphamide on the infiltration of CD11 b ${ }^{+}$Ly6CGr-1 ${ }^{-}$MDSCs (B). BBP increased S100A8 (C) and S100A9 (D) expression of MDSCs in the tumors after doxorubicin/cyclophosphamide treatment. 4T1 cells were implanted into the mammary fat pads of BALB/c mice, which were then randomly divided into 2 groups: the BBP-treated group was given i.p. with BBP (500 mg/kg of body weight, 3 times/week) while the control group was given an equal volume of normal saline. Tumor-bearing mice were sacrificed 28 days after transplantation. Two subgroups of MDSCs, CD11 $\mathrm{b}^{+} \mathrm{Ly} 6 \mathrm{CGr}-1^{+}$and $\mathrm{CD} 1 \mathrm{~b}^{+} \mathrm{Ly} 6 \mathrm{CGr}-1^{-}$, were isolated from the mammary tumors (4T1). The proteins in the supernatant of isolated cells were determined by ELISA kits. The sub-groups of immune cells were determined by staining of surface markers and by flow cytometric analysis. All results are representative of at least three independent experiments, and each value is the mean \pm SD of three determinations. The results are reported as mean $\pm \mathrm{SD} ;{ }^{*} \mathrm{P}<0.05$.

MDSCs (Fig. 5A). However, BBP exposure did not further increase the recruitment of CD11b ${ }^{+}$Ly6CGr-1- MDSCs, regardless of doxorubicin/cyclophosphamide treatment in the mice (Fig. 5B). Next, we assessed the expression of S100A8 and S100A9 in the tumor-infiltrating CD11b+Ly6CGr-1 ${ }^{+}$ MDSCs. ELISA results showed that BBP or doxorubicin/ cyclophosphamide treatment alone slight enhanced the expression of S100A8 and S100A9 in the CD11b ${ }^{+} \mathrm{Ly} 6 \mathrm{CGr}-1^{+}$ MDSCs (Fig. 5C and D). However, exposure of mice to BBP markedly enhanced the production of S100A8 and S100A9 in the CD11b+Ly6CGr-1+ MDSCs in the doxorubicin/cyclophosphamide-treated mice (Fig. 5C and D).

BBP increases angiogenesis by TADC-derived CXCL1/GRO $\alpha$. Since CXCL1/GRO $\alpha$ has been indicated to be an angiogenic factors in cancer (33), we assessed the effect of BBP on angiogenesis induced by TADCs. Compared to mdDC-CM, TADCs increased the tube formation of HUVECs. In addition, BBP increased the stimulatory effect of TADCs on tube formation (Fig. 6A). The synergistic effect of BBP on angiogenesis was prevented by the neutralizing CXCL1/GRO $\alpha$ antibody (Fig. 6B), suggesting that CXCL1/GRO $\alpha$ is the major angiogenic factor in TADC-mediated angiogenesis. Furthermore, exposure of mice to BBP increased the angiogenesis in primary breast cancers in vivo (Fig. 6C). To investigate whether targeting CXCL1/GRO $\alpha$ may be a strategy to prevent BBP-induced angiogenesis, we administered the mice with neutralizing CXCL1/GRO $\alpha$ antibody. Exposure of mice to $\mathrm{BBP}$ or chemotherapy increased the angiogenesis in the breast cancer. The enhancement of angiogenesis induced by BBP was prevented by the administration of the CXCL1/GRO $\alpha$ antibody in the chemotherapy and BBP + chemotherapy-treated mice (Fig. 6D).

\section{Discussion}

Exposure to phthalates causes various health and reproductive problems in human. Since phthalate esters are ubiquitous in the environment and the potential for adverse effects on human health is great, an understanding of how these factors 
A

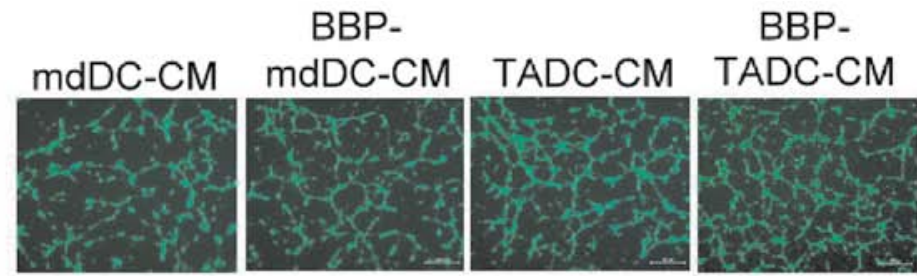

B

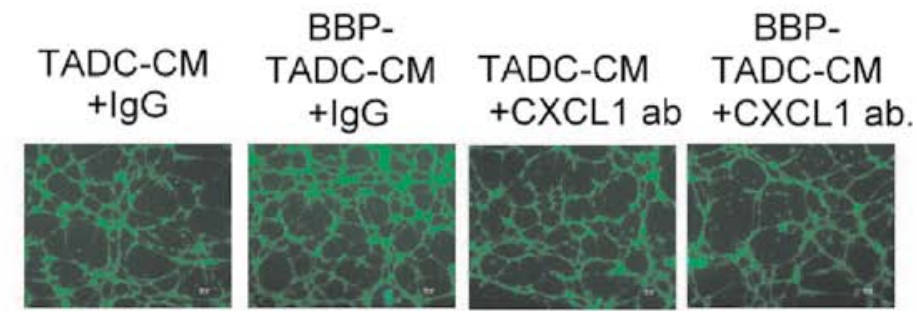

C

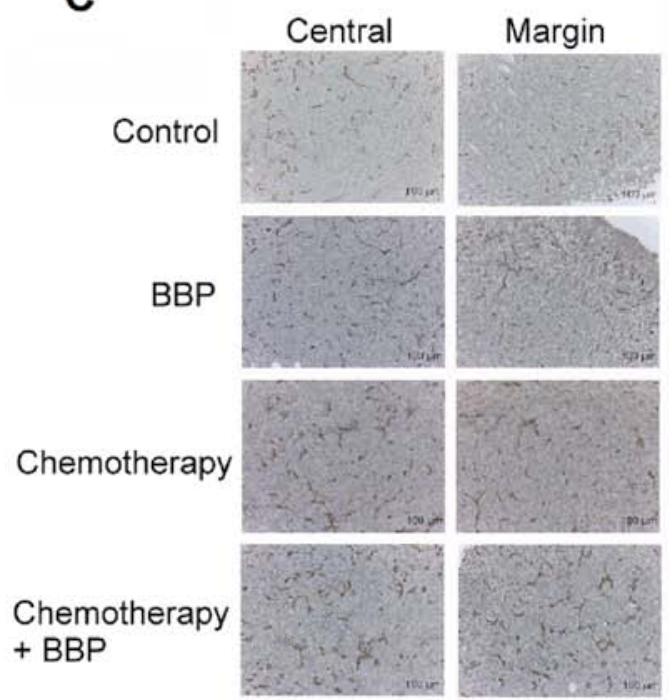

D

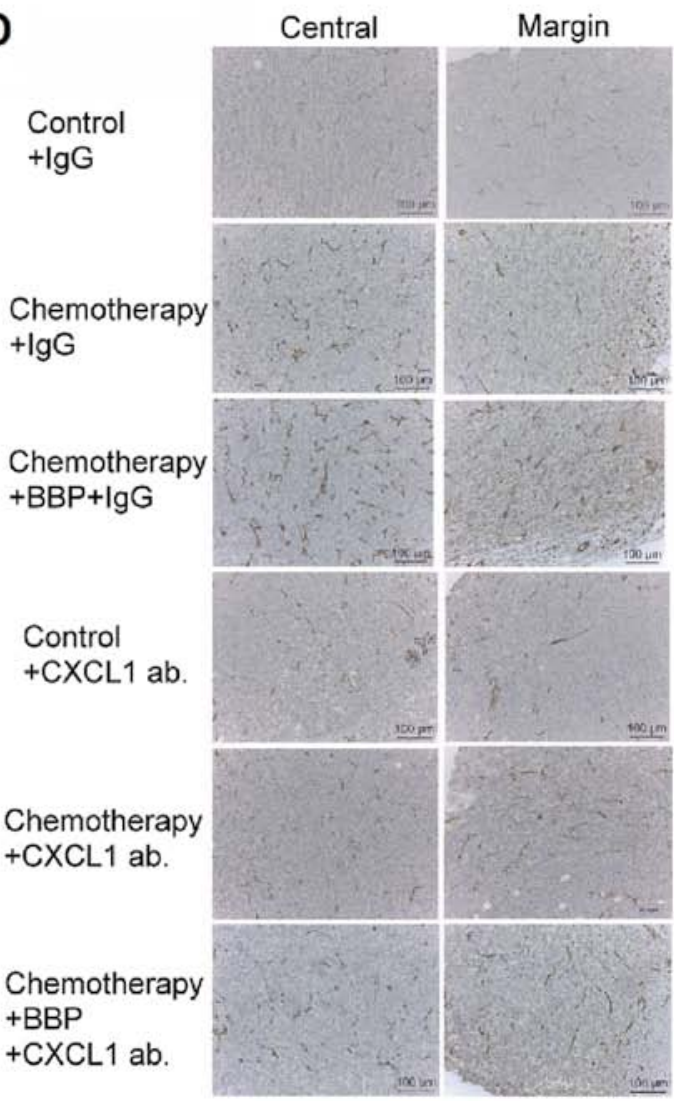

Figure 6. BBP increased the angiogenesis of cancer. (A) The CM of BBP-TADCs increased the tube formation of HUVECs. (B) Inhibition of CXCL1/GRO $\alpha$ prevented BBP-TADC-CM-mediated angiogenesis. HUVECs were cultured in various CMs with or without the IgG/CXCL1 antibody in a Matrigel-coated 48-well. Cells were stained by Calcein-AM and examined by fluorescence microscope. (C) BBP increased the angiogenesis in vivo. (D) Blockade of CXCL1/ GRO $\alpha$ decreased BBP-mediated angiogenesis in mice. $4 \mathrm{~T} 1$ cells were implanted into the mammary fat pads of BALB/c mice. The mice were then randomly divided into 4 groups: a control group, a doxorubicin hydrochloride $(2 \mathrm{mg} / \mathrm{kg}$ body weight) and cyclophosphamide monohydrate (60 mg/kg body weight) (1 time/week, i.p.) administration group, a doxorubicin/cyclophosphamide + BBP (500 mg/kg body weight $)+\operatorname{IgG}(50 \mu \mathrm{g} / \mathrm{mouse} / \mathrm{week})$ group, and a doxorubicin/cyclophosphamide + BBP + CXCL1 antibody (50 $\mu \mathrm{g} / \mathrm{mouse} /$ week) group. Angiogenesis of mammary tumors (4T1) was determined by CD31 staining.

influence human health and the underlying mechanisms are urgently required. This study is the first to investigate the influence of BBP on the chemoresistance of cancer. BBP caused TADCs to produce S100A8/A9, which directly decreased the sensitivity of breast cancer cells to doxorubicin/cyclophosphamide treatment. In addition, BBP also stimulated TADCs to secrete $\mathrm{CXCL} 1 / \mathrm{GRO} \alpha$, which increased the angiogenesis in the tumors, resulting in increased metastasis of breast cancer.
This study raises the possible impact of BBP on the chemotherapy of breast cancer.

Chronic inflammation is strongly associated with tumor initiation, progression, angiogenesis and drug resistance $(34,35)$. Elevated inflammatory factors within the TME have been reported to mediate chemotherapeutic resistance in cancers $(31,36,37)$. Infiltrating immune cells are an abundant component of solid tumors, and have been implicated as the 


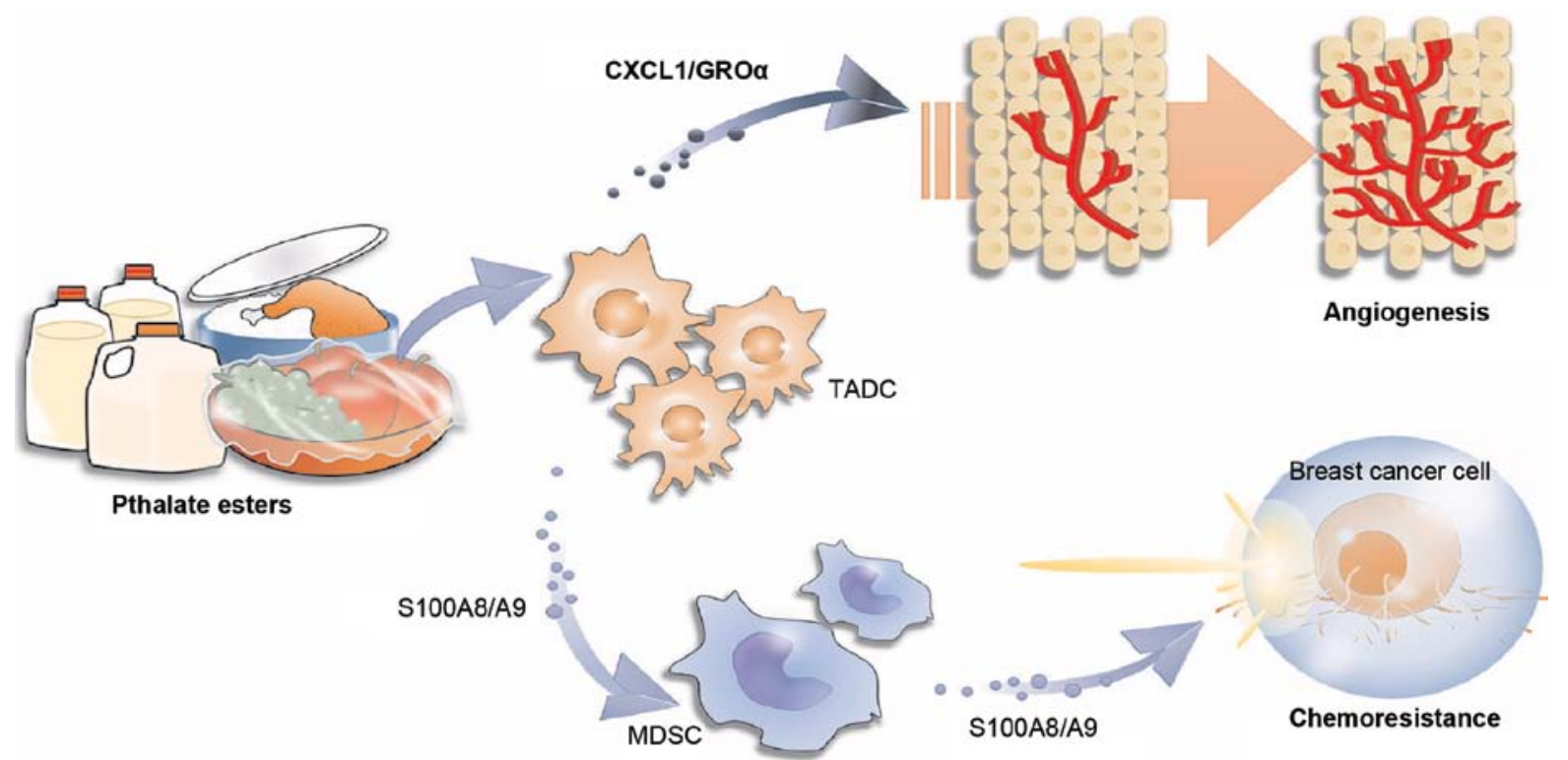

Figure 7. Proposed scheme illustrating that benzyl butyl phthalate (BBP) induces a change in the chemosensitivity of breast cancer to doxorubicin/cyclophosphamide by altering the cancer microenvironment.

major source of inflammatory cytokines/chemokines $(35,38)$. Our data demonstrated that TADCs decreased the sensitivity of breast cancer to doxorubicin/cyclophosphamide treatment, and this effect was further exacerbated by BBP exposure. The chemoresistance of breast cancer occurred by decreasing doxorubicin/cyclophosphamide-induced apoptotic cell death, while cancer cells were nourished by BBP-stimulated TADCs. This study suggests that paracrine signals potentiated by BBP in the TME maintain cancer survival despite cytotoxic insults.

S100A8 and S100A9, EF-hand calcium-binding proteins, are recognized as pro-inflammatory factors, which contribute to various human diseases, including cancer. S100A8 and S100A9 are constitutively expressed by myeloid cells, including granulocytes, monocytes, dendritic cells and osteoclasts, but not by lymphocytes (39). Increased levels of S100A8/A9 produced by cancer and stroma cells within the TME are found in many types of cancers, including gastric, esophageal, colon, pancreatic, bladder, ovarian, thyroid and breast cancer $(39,40)$. S100A8 and S100A9 proteins are considered to contribute to the overall pathogenesis of malignancies, including tumorigenesis, progression, metastasis and chemoresistance. S100A8 enhances drug resistance by increasing autophagy in leukemia cells (41). S100A8/A9 protect breast cancer cells from doxorubicin by increasing the activation of ERK1/2 and p70S6K (41). We found that BBP may increase the concentration of S100A8/A9 by two routes. First, BBP potentiates the stimulatory effect of breast cancer cells on the expression of S100A8/A9 in TADCs. Inhibition of S100A8 by siRNA prevents TADC-CM-mediated chemoresistance, supporting the specificity of the relationship of S100A8/9 with doxorubicin/cyclophosphamide resistance in breast cancer. The second source of S100A8/A9 is tumor-infiltrating MDSCs. BBP not only directly enhanced S100A8/A9 secretion, but also potentiated the hyperactivation of chemotherapy on the enhancement of S100A8 and S100A9 in tumor-infiltrating CD11b+Ly6CGr-1+ MDSCs. Elevated S100A9 levels are found in breast cancer patients after chemotherapy treatment, and this is considered to be a critical factor contributing to chemoresistance (41). The multiple effects of BBP on the expression of S100A8/A9 could provide survival signaling to breast cancer cells, enabling them to resist chemotherapy.

CXCL1/GRO $\alpha$ is an inflammatory chemokine and potent angiogenic and lymphangiogenic growth factors, which are mediators that potentiate cancer progression and chemoresistance $(31,42,43)$. Phthalate esters have been indicated to induce macrophages to express inflammatory cytokine CXCL1/GRO $\alpha$, which is implicated as a mediator of tumor angiogenesis $(43,44)$. The present study found that BBP increased the expression of CXCL1/GRO $\alpha$ in TDACs in vitro and in vivo. Knockdown of CXCL1/GRO $\alpha$ by siRNA did not affect either TADC-CM or BBP-TADC-CM-mediated chemoresistance, suggesting they are not directly involved in the protection of cancer from anticancer drugs. However, blockade of CXCL/GRO $\alpha$ by a neutralizing antibody decreased angiogenesis after doxorubicin/cyclophosphamide treatment in vivo, suggesting that CXCL1/GRO $\alpha$ enhanced the development of BBP-mediated cancer relapse after chemotherapy by altering tumor angiogenesis.

This is the first study to explore the influence of BBP on chemotherapy in breast cancer. BBP stimulated TADCs and MDSCs to express S100A8/A9, which provided a direct protective effect against chemotherapy. BBP also increased TADCs to produce CXCL1/GRO $\alpha$, which enhanced the angiogenesis in breast cancer, resulting in increased cancer metastasis after chemotherapy (Fig. 7). This study highlights the potential interference of phthalate esters on the treatment of breast cancer with specific therapeutic regimens.

\section{Acknowledgements}

This study was supported by grants from the National Science Council of Taiwan (NSC 101-2628-B-037001-MY3; NSC 101-2320-B-037-043-MY3; NSC 
102-2628-B-037-002-MY3; NSC 102-2632-B-037-001-MY3; and NSC 102-2314-B-037-035-MY3), the Ministry of Science and Technology (MOST 103-2320-B-037-006-MY3 and MOST 103-2314-B-037-052), the Excellence for Cancer Research Center Grant, the Ministry of Health and Welfare, Executive Yuan, Taipei, Taiwan (MOHW 103-TD-B-111-05), the Kaohsiung Medical University 'Aim for the Top 500 Universities Grant, grant no. KMU-DT103008', and the Kaohsiung Medical University 'Aim for the Top Universities Grant, grant nos. KMU-TP103A19 and KMU-TP103A20'.

\section{References}

1. Cirillo T, Fasano E, Castaldi E, Montuori $P$ and Amodio Cocchieri R: Children's exposure to Di(2-ethylhexyl) phthalate and dibutylphthalate plasticizers from school meals. J Agric Food Chem 59: 10532-10538, 2011.

2. Casajuana $\mathrm{N}$ and Lacorte $\mathrm{S}$ : New methodology for the determination of phthalate esters, bisphenol A, bisphenol A diglycidyl ether, and nonylphenol in commercial whole milk samples. J Agric Food Chem 52: 3702-3707, 2004.

3. Wu Z, Zhang X, Wu X, Shen G, Du Q and Mo C: Uptake of di(2-ethylhexyl) phthalate (DEHP) by the plant Benincasa hispida and its use for lowering DEHP content of intercropped vegetables. J Agric Food Chem 61: 5220-5225, 2013.

4. Liu Y, Wang S and Wang L: Development of rapid determination of 18 phthalate esters in edible vegetable oils by gas chromatography tandem mass spectrometry. J Agric Food Chem 61: 1160-1164, 2013.

5. Yan H, Cheng X and Yang G: Dummy molecularly imprinted solid-phase extraction for selective determination of five phthalate esters in plastic bottled functional beverages. J Agric Food Chem 60: 5524-5531, 2012.

6. Sun H, Yang Y, Li H, Zhang J and Sun N: Development of multiresidue analysis for twenty phthalate esters in edible vegetable oils by microwave-assisted extraction-gel permeation chromatography-solid phase extraction-gas chromatography-tandem mass spectrometry. J Agric Food Chem 60: 5532-5539, 2012.

7. Fu X and Du Q: Uptake of di-(2-ethylhexyl) phthalate of vegetables from plastic film greenhouses. J Agric Food Chem 59: 11585-11588, 2011.

8. Guo Y, Zhang Z, Liu L, Li Y, Ren N and Kannan K: Occurrence and profiles of phthalates in foodstuffs from China and their implications for human exposure. J Agric Food Chem 60: 6913-6919, 2012.

9. Cirillo T, Latini G, Castaldi MA, Dipaola L, Fasano E, Esposito F, Scognamiglio G, Francesco FD and Cobellis L: Exposure to di-2-ethylhexyl phthalate, di-n-butyl phthalate and bisphenol A through infant formulas. J Agric Food Chem 63: 3303-3310, 2015.

10. Gaspar FW, Castorina R, Maddalena RL, Nishioka MG, McKone TE and Bradman A: Phthalate exposure and risk assessment in California child care facilities. Environ Sci Technol 48: 7593-7601, 2014.

11. Hsieh TH, Tsai CF, Hsu CY, Kuo PL,Lee JN, Chai CY, Wang SC and Tsai EM: Phthalates induce proliferation and invasiveness of estrogen receptor-negative breast cancer through the AhR/HDAC6/c-Myc signaling pathway. FASEB J 26: 778-787, 2012.

12. Carran M and Shaw IC: New Zealand Malayan war veterans' exposure to dibutylphthalate is associated with an increased incidence of cryptorchidism, hypospadias and breast cancer in their children. NZ Med J 125: 52-63, 2012.

13. Fernandez SV and Russo J: Estrogen and xenoestrogens in breast cancer. Toxicol Pathol 38: 110-122, 2010.

14. Chen FP and Chien MH: Lower concentrations of phthalates induce proliferation in human breast cancer cells. Climacteric 17: 377-384, 2014

15. Hsieh TH, Tsai CF, Hsu CY, Kuo PL, Hsi E, Suen JL, Hung CH, Lee JN, Chai CY, Wang SC, et al: n-Butyl benzyl phthalate promotes breast cancer progression by inducing expression of lymphoid enhancer factor 1. PLoS One 7: e42750, 2012.

16. Hsieh TH, Tsai CF, Hsu CY, Kuo PL, Lee JN, Chai CY, Hou MF, Chang CC, Long CY, Ko YC, et al: Phthalates stimulate the epithelial to mesenchymal transition through an HDAC6-dependent mechanism in human breast epithelial stem cells. Toxicol Sci 128: 365-376, 2012.
17. Torre LA, Bray F, Siegel RL, Ferlay J, Lortet-Tieulent J and Jemal A: Global cancer statistics, 2012. CA Cancer J Clin 65: 87-108, 2015.

18. Ferlay J, Soerjomataram I, Dikshit R, Eser S, Mathers C, Rebelo M, Parkin DM, Forman D and Bray F: Cancer incidence and mortality worldwide: Sources, methods and major patterns in GLOBOCAN 2012. Int J Cancer 136: E359-E386, 2015.

19. Roché H and Vahdat LT: Treatment of metastatic breast cancer: Second line and beyond. Ann Oncol 22: 1000-1010, 2011.

20. Hu G, Chong RA, Yang Q, Wei Y, Blanco MA, Li F, Reiss M, $\mathrm{Au}$ JL, Haffty BG and Kang Y: MTDH activation by $8 \mathrm{q} 22$ genomic gain promotes chemoresistance and metastasis of poor-prognosis breast cancer. Cancer Cell 15: 9-20, 2009.

21. Klemm F and Joyce JA: Microenvironmental regulation of therapeutic response in cancer. Trends Cell Biol 25: 198-213, 2015.

22. Grivennikov SI, Greten FR and Karin M: Immunity, inflammation, and cancer. Cell 140: 883-899, 2010.

23. Weizman N, Krelin Y, Shabtay-Orbach A, Amit M, Binenbaum Y, Wong RJ and Gil Z: Macrophages mediate gemcitabine resistance of pancreatic adenocarcinoma by upregulating cytidine deaminase. Oncogene 33: 3812-3819, 2014.

24. Mitchem JB, Brennan DJ, Knolhoff BL, Belt BA, Zhu Y, Sanford DE, Belaygorod L, Carpenter D, Collins L, PiwnicaWorms D, et al: Targeting tumor-infiltrating macrophages decreases tumor-initiating cells, relieves immunosuppression, and improves chemotherapeutic responses. Cancer Res 73: 1128-1141, 2013.

25. Hsu YL, Hung JY, Tsai YM, Tsai EM, Huang MS, Hou MF and Kuo PL: 6-shogaol, an active constituent of dietary ginger, impairs cancer development and lung metastasis by inhibiting the secretion of CC-chemokine ligand 2 (CCL2) in tumor-associated dendritic cells. J Agric Food Chem 63: 1730-1738, 2015.

26. Kan JY, Wu DC, Yu FJ, Wu CY, Ho YW, Chiu YJ, Jian SF, Hung JY, Wang JY and Kuo PL: Chemokine (C-C motif) ligand 5 is involved in tumor-associated dendritic cell-mediated colon cancer progression through non-coding RNA MALAT-1. J Cell Physiol 230: 1883-1894, 2015.

27. Kuo PL, Huang MS, Cheng DE, Hung JY, Yang CJ and Chou SH: Lung cancer-derived galectin-1 enhances tumorigenic potentiation of tumor-associated dendritic cells by expressing heparin-binding EGF-like growth factor. J Biol Chem 287: 9753-9764, 2012.

28. Tang XH, Deng S, Li M and Lu MS: The anti-tumor effect of cross-reacting material 197, an inhibitor of heparin-binding EGF-like growth factor, in human resistant ovarian cancer. Biochem Biophys Res Commun 422: 676-680, 2012.

29. Qian DZ, Rademacher BL, Pittsenbarger J, Huang CY, Myrthue A, Higano CS, Garzotto M, Nelson PS and Beer TM: CCL2 is induced by chemotherapy and protects prostate cancer cells from docetaxel-induced cytotoxicity. Prostate 70: 433-442, 2010.

30. Lee E, Lee SJ, Koskimaki JE, Han Z, Pandey NB and Popel AS: Inhibition of breast cancer growth and metastasis by a biomimetic peptide. Sci Rep 4: 7139, 2014.

31. Acharyya S, Oskarsson T, Vanharanta S, Malladi S, Kim J, Morris PG, Manova-Todorova K, Leversha M, Hogg N, Seshan VE, et al: A CXCL1 paracrine network links cancer chemoresistance and metastasis. Cell 150: 165-178, 2012.

32. Wang L, Chang EWY, Wong SC, Ong SM, Chong DQY and Ling KL: Increased myeloid-derived suppressor cells in gastric cancer correlate with cancer stage and plasma S100A8/A9 proinflammatory proteins. J Immunol 190: 794-804, 2013.

33. Miyake M, Goodison S, Urquidi V, Gomes Giacoia E and Rosser CJ: Expression of CXCL1 in human endothelial cells induces angiogenesis through the CXCR2 receptor and the ERK1/2 and EGF pathways. Lab Invest 93: 768-778, 2013.

34. Palucka K, Coussens LM and O'Shaughnessy J: Dendritic cells, inflammation, and breast cancer. Cancer J 19: 511-516, 2013.

35. Coussens LM, Zitvogel L and Palucka AK: Neutralizing tumor-promoting chronic inflammation: A magic bullet? Science 339: 286-291, 2013.

36. Hartmann TN, Burger JA, Glodek A, Fujii N and Burger M: CXCR4 chemokine receptor and integrin signaling co-operate in mediating adhesion and chemoresistance in small cell lung cancer (SCLC) cells. Oncogene 24: 4462-4471, 2005.

37. Angst E, Reber HA, Hines OJ and Eibl G: Mononuclear cell-derived interleukin-1 beta confers chemoresistance in pancreatic cancer cells by upregulation of cyclooxygenase- 2 . Surgery 144: 57-65, 2008

38. Chen R, Alvero AB, Silasi DA and Mor G: Inflammation, cancer and chemoresistance: Taking advantage of the toll-like receptor signaling pathway. Am J Reprod Immunol 57: 93-107, 2007. 
39. Srikrishna G: S100A8 and S100A9: New insights into their roles in malignancy. J Innate Immun 4: 31-40, 2012.

40. Ichikawa M, Williams R, Wang L, Vogl T and Srikrishna G: S100A8/A9 activate key genes and pathways in colon tumor progression. Mol Cancer Res 9: 133-148, 2011.

41. Yang M, Zeng P, Kang R, Yu Y, Yang L, Tang D and Cao L: S100A8 contributes to drug resistance by promoting autophagy in leukemia cells. PLoS One 9: e97242, 2014

42. Zou A, Lambert D, Yeh H, Yasukawa K, Behbod F, Fan F and Cheng N: Elevated CXCL1 expression in breast cancer stroma predicts poor prognosis and is inversely associated with expression of TGF- $\beta$ signaling proteins. BMC Cancer 14: 781, 2014.
43. Pecot CV, Rupaimoole R, Yang D, Akbani R, Ivan C, Lu C, Wu S, Han HD, Shah MY, Rodriguez-Aguayo C, et al: Tumour angiogenesis regulation by the miR-200 family. Nat Commun 4: 2427,2013

44. Nishioka J, Iwahara C, Kawasaki M, Yoshizaki F, Nakayama H, Takamori K, Ogawa H and Iwabuchi K: Di-(2-ethylhexyl) phthalate induces production of inflammatory molecules in human macrophages. Inflamm Res 61: 69-78, 2012. 